\title{
Cutaneous Malignant Melanoma 2
}

National Cancer Institute

\section{Source}

National Cancer Institute. Cutaneous Malignant Melanoma 2. NCI Thesaurus. Code C128801.

An autosomal dominant genetic disorder caused by mutations in the CDKN2A gene, encoding cyclin-dependent kinase inhibitor 2A. The condition is characterized by cutaneous malignant melanoma associated with this genetic alteration. 